\title{
Montelukast Efficiency in Improving the Deleterious Gastrointestinal Effects of Dexamethasone in Rats
}

\author{
GHADA F. SOLIMAN, M.D.*; MARIAN Y. WISSA, M.D.* and HEBA MORSI, M.D.** \\ The Departments of Medical Pharmacology* and Medical Biochemistry \& Molecular Biology**, Faculty of Medicine, \\ Cairo University, Egypt
}

\begin{abstract}
Background: Montelukast and dexamethasone are used in combination in the treatment of asthma. Treatment by steroids resulted in gastric mucosa weakening enhancing the occurrence of ulcer in addition to its effect on the motility and contractility of gastrointestinal tract.

Aim of Study: The present study was designed to evaluate the anti-ulcer effect of montelukast, a selective leukotriene (LT) D4 receptor antagonist compared to famotidine and its effect on the motility and contractility of the small intestine in gastric ulcer induced by dexamethasone and aggravated by cold stress.
\end{abstract}

Material and Methods: Adult male rats were divided into 5 groups: The first received normal saline. The other groups were given dexamethasone intraperitoneally $(4 \mathrm{mg} / \mathrm{kg} /$ day $)$ for 5 days. The third group received famotidine $40 \mathrm{mg} / \mathrm{kg} /$ day while the fourth and fifth groups received montelukast 30 and $60 \mathrm{mg} / \mathrm{kg} /$ day orally respectively thirty minutes after dexamethasone. At the end, rats were exposed to cold stress then sacrificed to extract the stomachs and intestines to determine gastric ulcer score and intestinal transit then the response of small intestine to acetyl choline was recorded. Then the stomachs were divided for histopathological and biochemical studies.

Results: Dexamethasone treatment resulted in ulceration of gastric mucosa, increased intestinal transit, diminished intestinal contraction and increased oxidative stress. The group treated with montelukast $60 \mathrm{mg} / \mathrm{kg} /$ day showed a significant decrease in mean gastric ulcer score, intestinal transit but increase of intestinal contractility. All treated groups showed significant MDA decrease, improved histopathological picture of the stomach while the two montelukast treated groups showed significant increase in SOD.

Conclusion: Montelukast with high dose shows a promising role in eliminating the undesirable effects induced by corticosteroids especially if associated with stress.

Key Words: Montelukast - Dexamethasone - Famotidine Intestinal transit-Gastric ulcer.

Correspondence to: Dr. Ghada F. Soliman,

E-Mail: ghadafsaleh@yahoo.com

\section{Introduction}

STEROID administration in animal studies was proved to impair both gastric mucus production and gastric bicarbonate secretion resulting in weakening of gastric mucosa [1]. Also it impaired both angiogenesis and repair of the epithelium experimentally [2,3]. Montelukast is a selective leukotriene (LT) D4 receptor antagonist, which has an antiasthmatic and anti-inflammatory effects $[4,5]$. It also possesses a range of secondary anti-inflammatory activities as inhibition of the enzymes 5lipoxygenase [6], histone acetyltransferase (HAT) [7], and adenosine 3',5'-cyclic monophosphate (cAMP) phosphodiesterase [8], as well as interference with purinergic $\mathrm{P} 2 \mathrm{Y}$ receptors [6], and inhibition of eosinophil adhesion to vascular endothelium and migration [9]. Famotidine is a well-known $\mathrm{H} 2$ antagonist which reduces acid secretion stimulated by histamine as well as by gastrin and cholinomimetic agents either by binding to the parietal cell $\mathrm{H} 2$ receptors blocking the histamine released from the enterochromaffin-like (ECL) cells by gastrin or vagal stimulation, or by decreasing acid secretion in response to direct stimulation of the parietal cell by gastrin or acetylcholine [10]

The present study was designed to evaluate the effect of montelukast compared to famotidine on peptic ulcer induced by dexamethasone and aggravated by cold stress and its effect on the motility and contractility of the small intestine, to detect the efficiency of montelukast to eliminate the undesirable effects induced by corticosteroids especially when associated with stress exposure.

\footnotetext{
List of Abbreviations:

MDA : Malondialdehyde.

SOD : Levels and superoxide dismutase.

SD : Standard Deviation.
} 


\section{Material and Methods}

\section{Animals:}

30 healthy adult male Sprague-Dawley rats, weighing $180-220 \mathrm{gm}$ were used in this study which was started from November 2017 to February 2019. They were bred in the animal house at Kasr ElAiny, Faculty of Medicine, Cairo University, and divided into 5 groups. Each group of rats was housed in a cage at ordinary room temperature, humidity, natural daily light dark cycle, and fed with the standard diet in the form of rodents' pellets and clean water. The rats were left for an initial adaptation period for at least one week before subjecting them to the experimental manipulation(s). All the experiments were carried out between 09.00 a.m. and 04.00 p.m. and were conducted in accordance with the regulations of the relevant clinical research ethics committee and with those of the Code of Ethics of the World Medical Association (Declaration of Helsinki).

\section{Drugs and chemicals:}

- Dexamethasone ampoules (Sigma-Tec Pharmaceutical Industries S.A.E.).

- Montelukast tablets (Merck Sharp and Dome Pharmaceuticals, Egypt) dissolved in distilled water immediately before use.

- Famotidine tablets (Spimaco PharmaceuticalsEgypt) dissolved in distilled water immediately before use.

- Acetylcholine powder (MP Biomedicals, USA), dissolved in distilled water immediately before use.

Kits: Superoxide dismutase manufactured by Cayman Chemical Company, Ann Arbor, MI, USA.

\section{Experimental design:}

The rats were divided into 5 groups (6 rats each) and subjected to the study for 5 days: The first and the second groups (control, diseased induced by dexamethasone group respectively): received normal saline and dexamethasone $(4 \mathrm{mg} /$ $\mathrm{kg}$ /day) intraperitoneally respectively [11]. The other three groups were given dexamethasone in the same dose and duration. Then after thirty minutes, the rats were treated as follows: The third group was treated with famotidine $40 \mathrm{mg} / \mathrm{kg} / \mathrm{day}$ orally [12], while the fourth and fifth groups were treated orally with montelukast at two doses, 30 and $60 \mathrm{mg} / \mathrm{kg} /$ day respectively.

At the end of the experiment; the rats were deprived of food but allowed free access to water the day before scarification. On scarification day, the rats were exposed to cold stress by enclosing each animal in a small cage to restrict its movement and was kept at a temperature of $4{ }^{\circ} \mathrm{C}$ for 2 hours [13].

\section{Measurement of Gastric ulcer score:}

The stomachs were immediately removed, opened along the greater curvature, washed with saline solution $(0.9 \% \mathrm{NaCl})$, fixed on a platform and examined with a magnifying lens. All the ulcerative lesions were accurately measured along their greater lengths and the ulcer score was recorded as the sum of the lengths of all lesions [14]

Afterwards, a portion of gastric tissue was fixed in $10 \%$ formol for histopathological examination and the remained tissue was homogenized in potassium phosphate buffer ( $\mathrm{pH}$ 7.4) using a Polytronmixer (Kinematica AG, Switzerland). The homogenate was centrifuged at $3000 \mathrm{~g}$ at $4^{\circ} \mathrm{C}$ for $10 \mathrm{~min}$ to yield a low-speed supernatant that was used to measure the biochemical parameters.

\section{Determination of small intestinal transit:}

The indicator substance was prepared by mixing ten grams of activated charcoal with $1 \mathrm{~g}$ gum Arabic in $100 \mathrm{~mL}$ of distilled water then $2 \mathrm{~mL}$ of such mixture was administered by oral gavage (through a straight metallic needle, 15 Gauge, $15 \mathrm{~cm}$ length with a blunt tip). Each animal was left for $60 \mathrm{~min}$ then was sacrificed by cervical decapitation. The abdomen was instantly cut open through the linea alba to decrease bleeding. The small intestine was cut starting from the duodenum, being the extension of the pyloric sphincter, to the ileum at the ileocecal sphincter which was also prominent at the cecal end. The small intestine was immediately straightened with identification of the location of the indicator. The total length of the small intestine and the length travelled by the indicator were measured by using a measuring tape and recorded. The small intestinal transit was calculated as: Length travelled by marker substance/Total length of small intestine $\mathrm{x} 100 \%$ [15]

\section{Determination of small intestinal contractility:}

After exposure of the intestine, the proximal ileum was identified and cut off, then placed in a container of Tyrode solution in which each liter is composed of $\left(200 \mathrm{mg} \mathrm{CaCl}_{2}, 8 \mathrm{gm} \mathrm{NaCl}, 200 \mathrm{mg}\right.$ $\mathrm{KCl}, 100 \mathrm{mg} \mathrm{MgCl}_{2}, 50 \mathrm{mg} \mathrm{NaH}{ }_{2} \mathrm{PO}_{4}, 1 \mathrm{gm}$ glucose, $1 \mathrm{gm} \mathrm{NaHCO} 3$ ) and aerated. The ileum was then cut into small segments of $3 \mathrm{~cm}$ in length and mounted at one end to a fixed support in an organ bath containing Tyrode solution. The other end of the ileum was fixed to a transducer of PowerLab (ADInstruments ML866; 430-0820). The tissue 
was left to equilibrate for $60 \mathrm{~min}$ during which, the bathing solution was replaced with fresh Tyrode solution at $15 \mathrm{~min}$ interval to avoid accumulation of metabolites. The tissue was then challenged with graded doses of acetylcholine (10-3mg), at an interval of $1 \mathrm{~min} /$ administration [16], then the results were recorded.

\section{Biochemical estimation:}

A small portion of the gastric tissue was kept in phosphate buffer, then homogenized using GlassCol® homogenizer, Terre Haute Indiana, USA. The cell-free homogenate was collected and stored at $-80^{\circ} \mathrm{C}$ for further analysis and estimation spectrophotometrically.

\section{Measurement of superoxide dismutase (SOD):}

Superoxide dismutases are metalloenzymes that catalyze the dismutation of the superoxide anion to molecular oxygen and hydroperioxide and thus form a crucial part of the cellular antioxidant defense mechanism [17]. It was estimated in gastric tissue, using a commercially available kit according to the manufacturers' protocols.

\section{Measurement of malondialdehyde (MDA):}

$20 \%$ TCA was added to $100 \mathrm{mg}$ gastric homogenate to precipitate the protein, and centrifuged. Supernatants were collected and thiobarbituric acid (TBA) solution was added to the supernatants. After boiling for 10 minutes in water bath, the absorbance was measured. Concentration of MDA in supernatants of gastric homogenate was calculated using the standard curve [18]

\section{Statistical analysis:}

The statistical package for social science (SPSS) version 21 (SPSS, Armonk, New York: International Business Machines Corporation) was used for data analysis. Simple descriptive statistics (arithmetic mean and standard deviation) were used for summary of quantitative data and frequencies used for qualitative data. One-way ANOVA and post-hoc tests were used to compare normally distributed quantitative data. The level of significance was set at probability $(p)$ value $<0.05$.

\section{Results}

\section{Mean gastric ulcer score:}

The rats treated with dexamethasone and exposed to cold stress developed ulceration of the gastric mucosa with a mean ulcer score $( \pm$ S.D. $)$ of $6.750 \pm 1.2550 \mathrm{~mm}$. Treatment of dexamethasonestress exposed rats with either famotidine or montelukast at both doses $(30$ and $60 \mathrm{mg} / \mathrm{kg}$ ) resulted in a decrease in the mean gastric ulcer score when compared to the dexamethasone-stress group. This decrease was significant in the group treated with montelukast $60 \mathrm{mg} / \mathrm{kg}(p<0.05)$. In addition, montelukast treatment at $60 \mathrm{mg} / \mathrm{kg}$ showed more decrease in the mean ulcer score than the other treated groups, and was significant when compared to the group treated with $30 \mathrm{mg} / \mathrm{kg}$ and the group treated with famotidine $(p<0.05)$. Moreover its mean ulcer score was insignificant when compared to the normal group $(p>0.05)$ (Table 1).

Table (1): The effect of treatment with montelukast $(30$ and $60 \mathrm{mg} / \mathrm{kg}$ ) and famotidine on the mean gastric ulcer score induced by dexamethasone-stress exposure.

\begin{tabular}{|c|c|c|c|c|c|}
\hline & Normal & Dexa/stress & Dexa/stress+Fam & Dexa/stress+Monte 30 & Dexa/stress+Monte 60 \\
\hline $\begin{array}{l}\text { Mean gastric ulcer } \\
\text { score } \pm \text { SDmm }\end{array}$ & $0.0 \pm 0.000$ & $6.750 \pm 1.2550^{\circ}$ & $4.750 \pm 1.5546^{\circ}$ & $4.583 \pm 1.7151^{\circ}$ & $1.500 \pm 0.8660 * \# \infty$ \\
\hline
\end{tabular}

\section{Intestinal transit:}

The dexamethasone-stress group showed an insignificant increase $(p>0.05)$ in intestinal transit $(52.6400 \pm 3.20383 \%)$ when compared to the normal group $(42.4333 \pm 5.10523 \%)$. Treatment with famotidine as well as montelukast caused a decrease in intestinal transit compared to the untreated dexamethasone-stress group that was significant in the group treated with $60 \mathrm{mg} / \mathrm{kg}$ montelukast $(p<0.05)$. Treatment with higher dose of montelukast $(60 \mathrm{mg} /$ $\mathrm{kg}$ ) also showed a significant decrease in intestinal transit (31.7500 \pm 3.46482$)$ when compared to the group treated with montelukast $30 \mathrm{mg} / \mathrm{kg}(49.8000 \pm$ 7.46659) which had an intestinal transit higher than the famotidine treated group (44.6667 \pm 2.15019 ) (Fig. 1). 
Effect of treatment with montelukast and famotidine on response of the small intestine to acetyl choline:

The rats exposed to induction of gastric ulcer by dexamethasone + stress showed an insignificant decrease in the intestinal contraction in response to acetyl choline at all concentrations compared to the normal rats. Treatment with either low dose montelukast (30mg/kg), high dose montelukast $(60 \mathrm{mg} / \mathrm{kg})$ or famotidine caused an increase in the intestinal contraction in response to acetyl choline at all concentrations compared to the untreated

Fig. (1): The effect of treatment with montelukast (30 and $60 \mathrm{mg} / \mathrm{kg}$ ) and famotidine on the mean intestinal transit in rats subjected to gastric ulcer induction by dexamethasone-stress exposure.

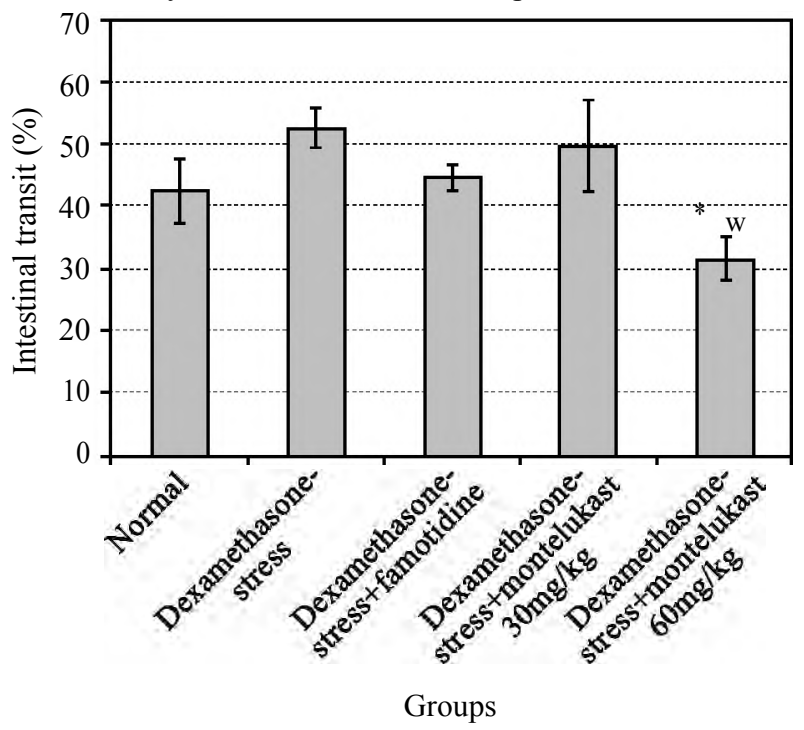

Fig. (1): The mean intestinal transit in all groups.

*, w: Significant compared to dexamethasone-stress group, dexamethasone-stress + montelukast $30 \mathrm{mg} / \mathrm{kg}$ group respectively.

Gastric tissue malondialdehyde (MDA) and super oxide dismutase (SOD):

The dexamethasone-stress ulcer group showed a significant increase in mean gastric tissue MDA compared to the normal group. Treatment with famotidine, montelukast low dose or high dose which recorded the lowest level caused a significant decrease in mean tissue levels of MDA compared to the untreated dexamethasone-stress group. The dexamethasone-stress group also showed a significant decrease in mean tissue SOD compared to the normal group. All the treated groups showed dexamethasone-stress group and the normal group. The highest response to acetyl choline at all concentrations was seen in the group treated with high dose of montelukast. The increase in the contractile response of this group was significant when compared to the normal and the untreated dexamethasone-stress groups at all concentrations. In addition, the contractile response of this group also showed a significant increase when compared to the famotidine treated group at 1 morgan bath (Figs. $2,3)$.

Fig. (2): The effect of treatment with montelukast (30 and $60 \mathrm{mg} / \mathrm{kg}$ ) and famotidine on the contractile response of small intestine to acetyl choline.
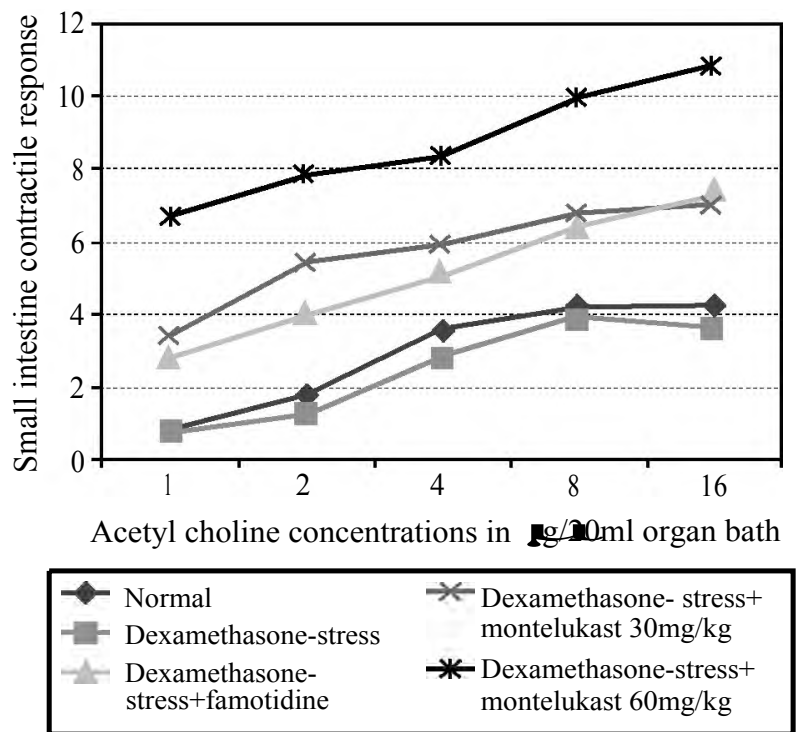

Fig. (2): The contractile response of the small intestine to acetyl choline at different concentrations in normal control and dexamethasone-stress groups compared to the groups treated with montelukast $(30$ and $60 \mathrm{mg}$ $/ \mathrm{kg}$ ) and famotidine.

a significant increase in mean SOD compared to dexamethasone-stress group except famotidine which showed an insignificant increase. Still, the mean tissue SOD was significantly lower than the normal group in all the treated groups except the group treated with high dose of montelukast which was insignificant from normal. The highest improvement in mean SOD levels was seen in the group treated with montelukast high dose and was insignificant when compared to montelukast low dose and significant when compared to famotidine treated group (Table 2). 

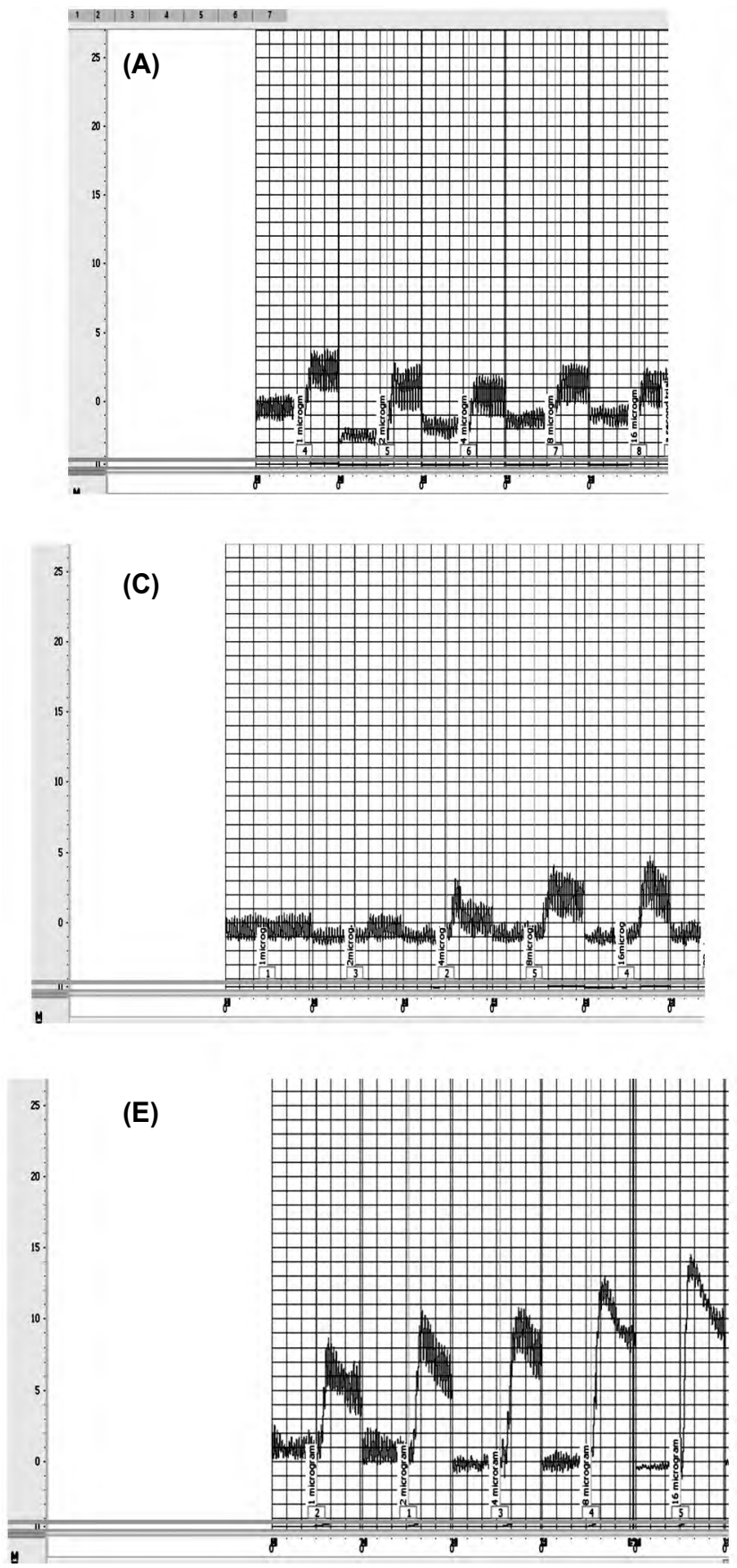
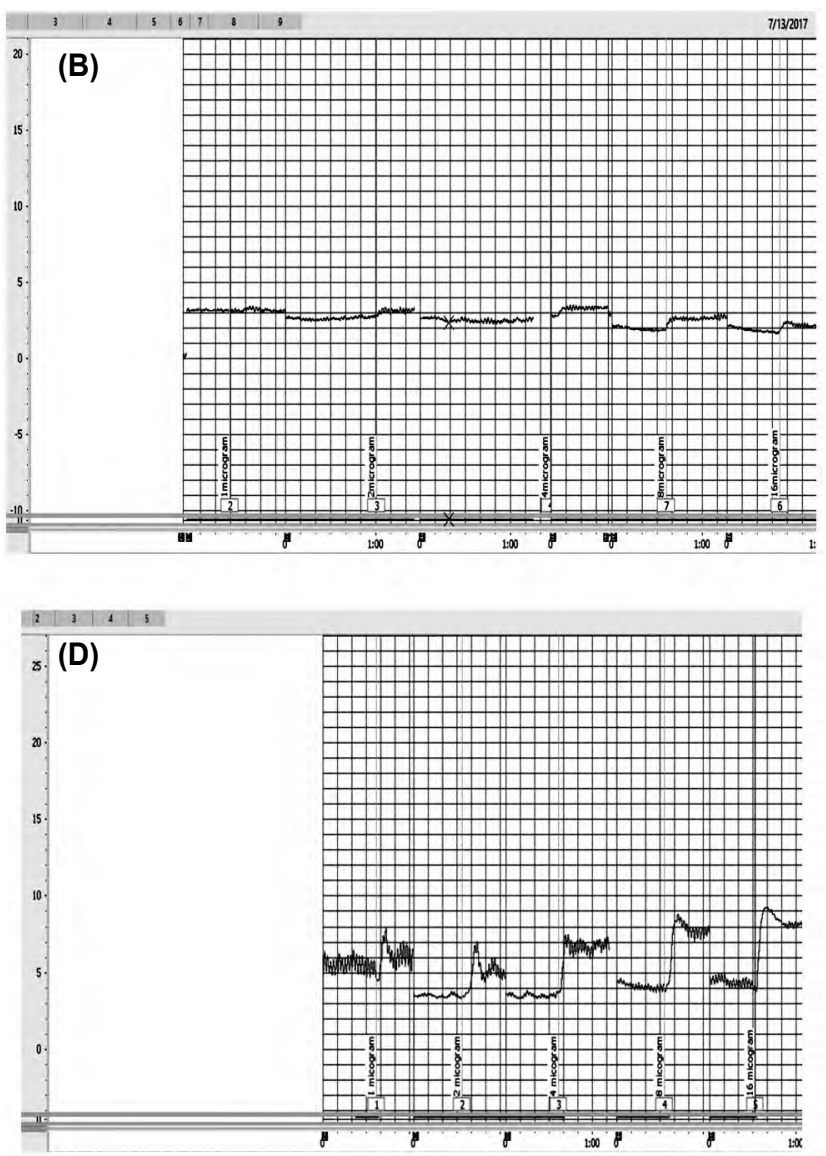

Fig. (3): Shows the different contractile response in all groups in which: (3a) Normal control group, (3b) Dexamethasone treated group, (3c) Dexamethasone and famotidine treated group, (3d) Dexamethasone and montelukast low dose treated group, (3e) Dexamethasone and montelukast high dose treated group.

Table (2): The effect of treatment with montelukast $(30 \mathrm{and} 60 \mathrm{mg} / \mathrm{kg}$ ) and famotidine on the mean gastric tissue malondialdehyde (MDA) and superoxide dismutase (SOD).

\begin{tabular}{cccccc}
\hline & Normal & Dexa/stress & Dexa/stress+Fam & Dexa/stress+Monte 30 & Dexa/stress+Monte 60 \\
\hline Mean tissue & $5.6640 \pm$ & $52.1200 \pm$ & $18.8400 \pm$ & $16.7400 \pm$ & $11.1200 \pm$ \\
MDA \pm SD & 0.94153 & $14.02095^{\circ}$ & $6.37519^{*}$ & $3.53879^{*}$ & $1.59280^{*}$ \\
nmol/g tissue & & & & & \\
Mean tissue & $3.0040 \pm$ & $0.8060 \pm$ & $1.5580 \pm$ & $2.1480 \pm$ & $2.5080 \pm$ \\
SOD \pm SD & 0.51486 & $0.28772^{\circ}$ & $0.40040^{\circ}$ & $0.46424^{*}$ & $0.35401^{* \#}$ \\
U/g tissue & & & & & \\
\hline
\end{tabular}

${ }^{\circ}$, ,\#: Significant compared to normal group, dexamethasone-stress group, dexamethasone-stress+famotidine group respectively. Level of significance is set at $p$-value $<0.05$.

Dexa/stress: Dexamethansone-stress group

Fam: Famotidine.

Monte 30, Monte 60: Montelukast 30 and $60 \mathrm{mg} / \mathrm{kg}$ respectively. 
Histopathological examination of the stomach:

Histopathological examination of the stomachs of normal rats revealed unremarkable pathological changes (Fig. 4: Photo $1 \mathrm{a}, \mathrm{b}$ ). The rats treated with dexamethasone and exposed to stress showed mucosal congestion, necrosis and disintegration with areas of congestion of the submucosa (Fig. 4: Photos 2 a,b,c,d).

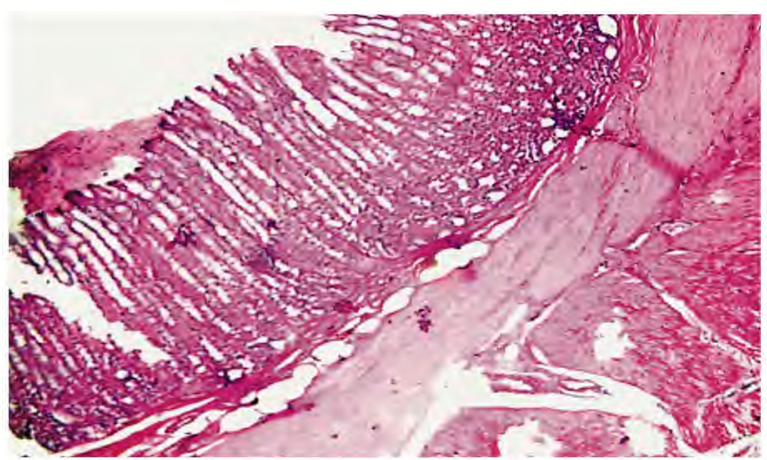

(1A)

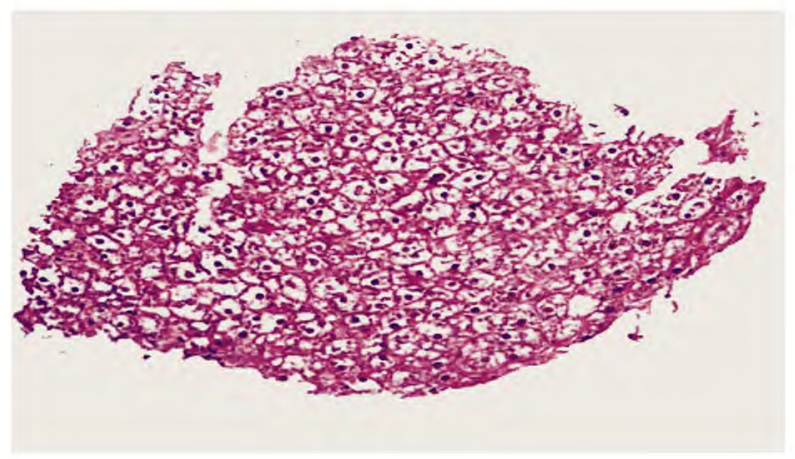

(2A)

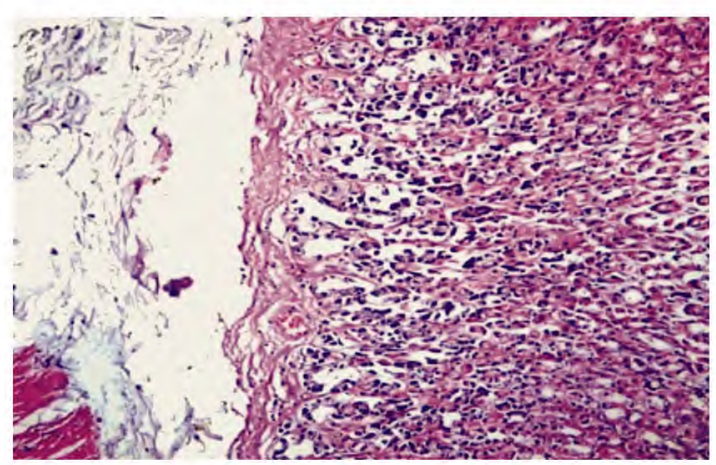

(2C)
The group treated with famotidine showed only some areas of submucosal congestion, otherwise the stomach structure was normal (Fig. 5: Photo 3 $a, b)$. The group treated with low dose of montelukast showed submucosal congestion (Fig. 5: Photo 4) while the group treated with high dose of montelukast showed mucosal epithelial regenerative changes with loss of mucin (Fig. 5: Photos 5 a,b).

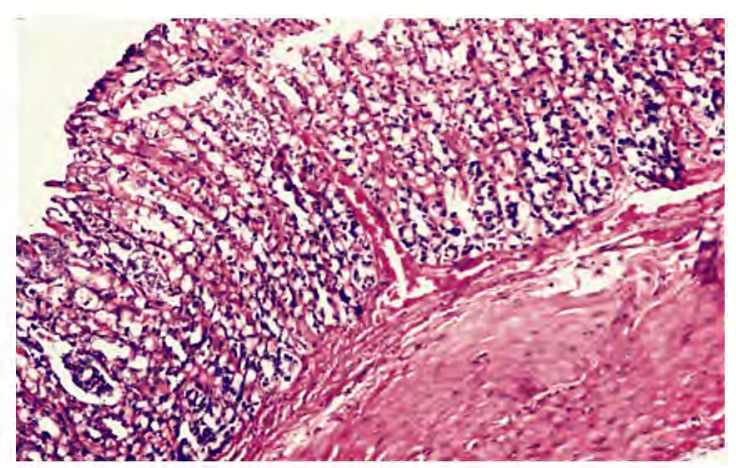

(1B)

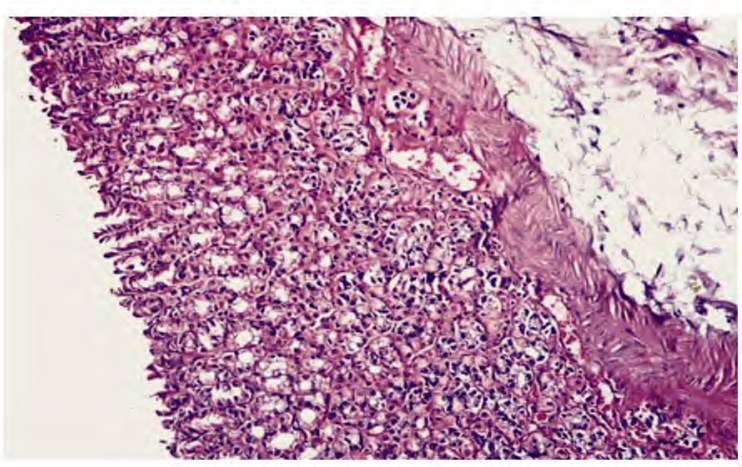

(2B)

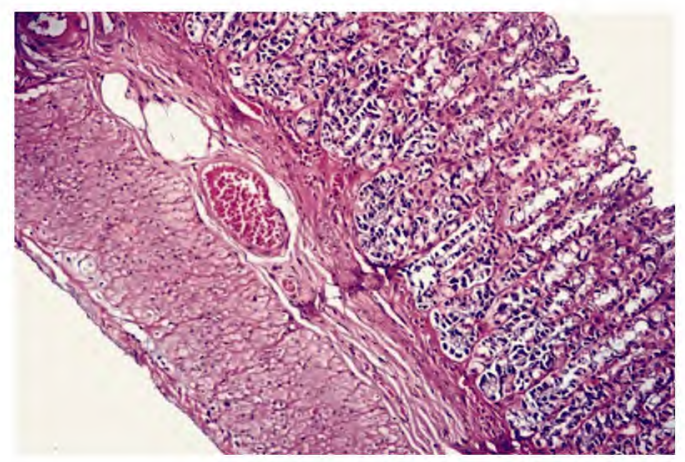

(2D)

Fig. (4): Photo (1a,b): A photomicrograph of gastric wall of normal rat shows no pathological changes in stomach of the rat (H\&Ex 100) jpg, Photo (2) A photomicrograph of transverse cross section of the stomach of rats treated with dexamethasone and exposed to stress (2a) Shows mucosal necrosis (H\&E X200) (2b) Shows mucosal congestion (H\&EX200) (2c) shows mucosal disintegration (H\&E X200)(2d) shows congestion in the submucosa (H\&E X200).

Fig. (4): Photos $(1,2)$ : Histopathological features of gastric wall of normal control and dexamethasone stress groups. 

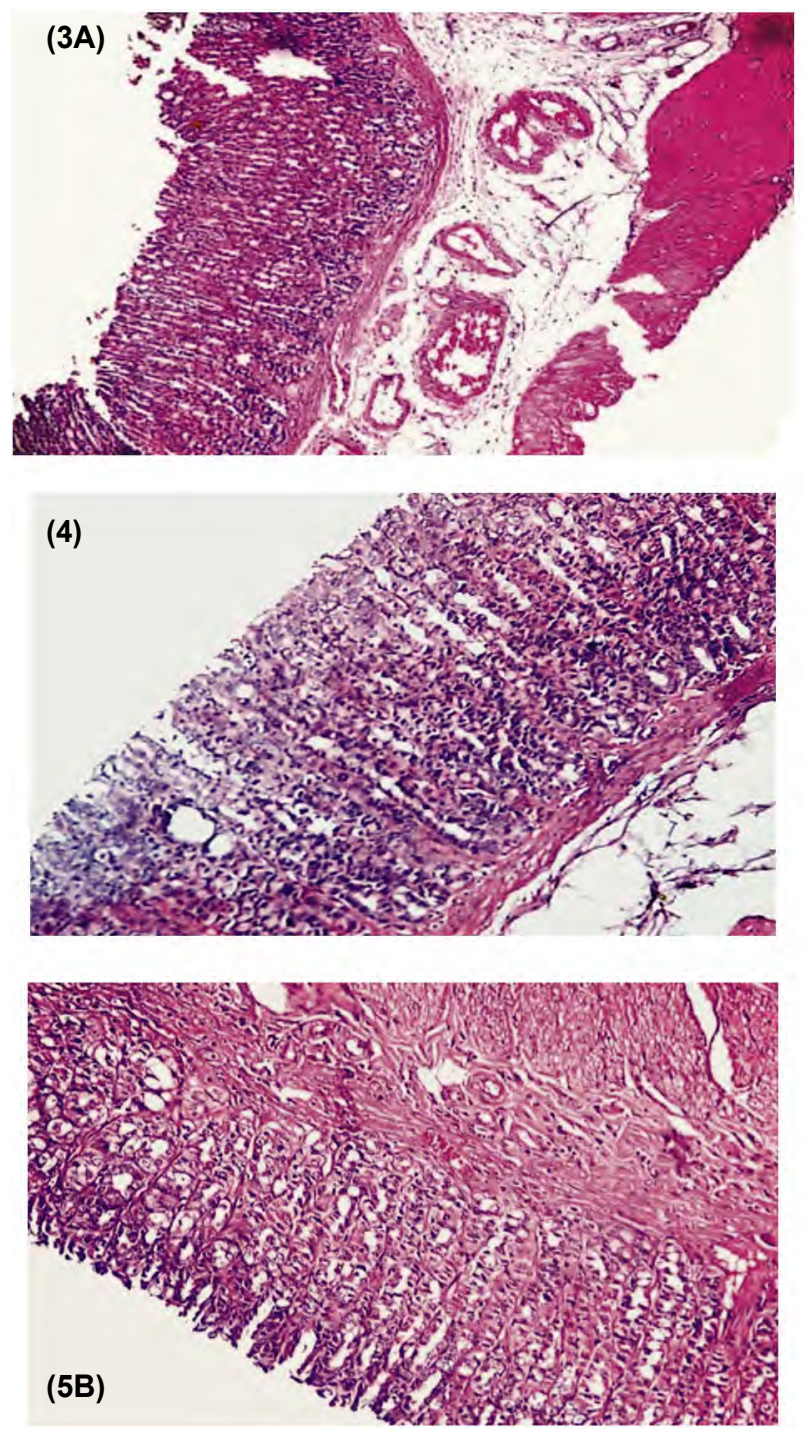

\section{Discussion}

The results of the present work demonstrated that exposure of rats to dexamethasone and cold stress resulted in gastric mucosal ulcers with histopathological examination showing mucosal necrosis and congestion of gastric submucosa. There was also elevation of gastric malondialdehyde (MDA) and decrease of superoxide dismutase (SOD). In accordance, Swamy et al. demonstrated that treatment of rats with dexamethasone for 10 days caused ulceration of gastric mucosa, decrease in SOD, reduced glutathione (GSH), and catalase with increase in MDA, myeloperoxidase (MPO) and alkaline phosphatase levels and on histopathological examination, dexamethasone caused edema, congestion, hemorrhage and necrosis of the stomach. They stated that these results may be due to several mechanisms like generation of free radicals, increase of oxidative stress, stimulation of gastric acid secretion, inhibition of arachidonic
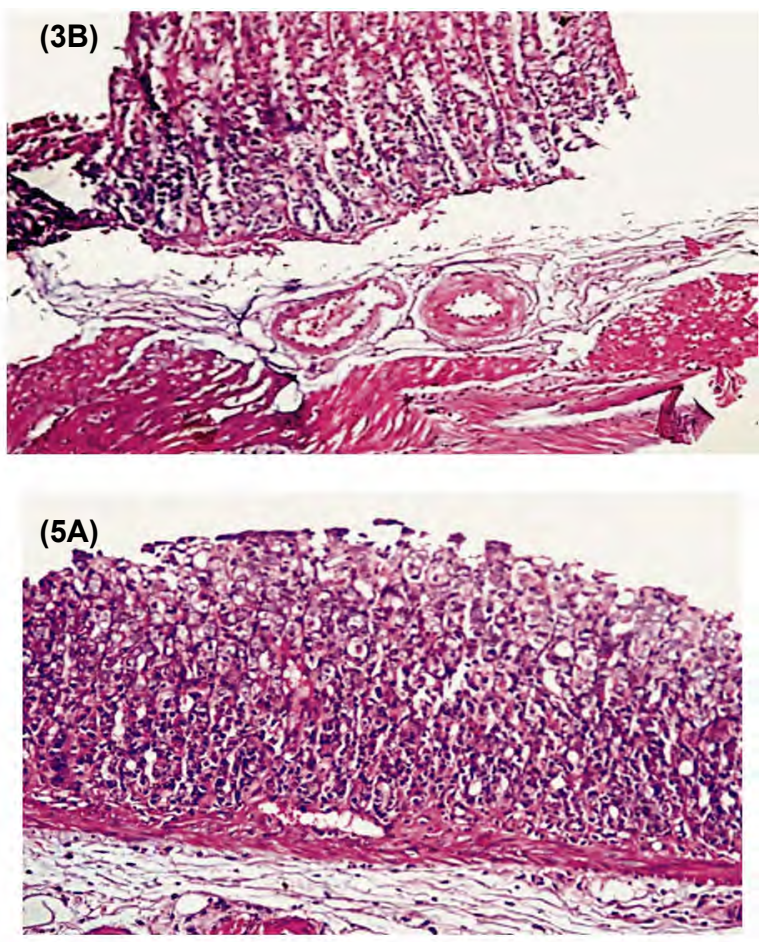

Fig. (5): Photo (3): Photomicrograph of gastric wall of rats treated with famotidine (H\&EX200) in which (3a) Shows vascular congestion in the submucosa, (3b) Submucosal congestion, Photo (4): A photomicrograph of transverse cross section of the stomach of rats treated with montelukast $(30 \mathrm{mg} / \mathrm{kg})$ shows submucosal congestion (H\&EX100), Photo (5): A photomicrograph of transverse cross section of the stomach of rats treated with montelukast $(60 \mathrm{mg} / \mathrm{kg})(\mathrm{H} \& \mathrm{EX} 200)$ in which (5a) Shows mucosal epithelial regenerative changes with loss of mucin while (5b) Shows mucosal epithelial regenerative changes.

Fig. (5): Photos $(3,4,5)$ : Histopathological features of gastric wall of all treated groups.

acid metabolism and inhibition of gastro-protective enzymes such as prostaglandin synthase and peroxidase. They added that dexamethasone suppresses epidermal growth factor-stimulated gastric epithelial cell proliferation which may lead to delayed ulcer healing that may be related to angiogenesis inhibition and decreasing epithelial regeneration in gastric ulcers [19].

A study conducted by Ersoy et al., 2008 showed that exposure of rats to water avoidance stress (WAS) daily for 5 days caused severe degeneration of gastric epithelium with dilatation and degeneration of gastric glands. Also prominent blood vessels congestion and inflammatory cell infiltration were observed in the gastric mucosa with the presence of granulated and degranulated mast cells with significant increase of gastric tissue MDA and decrease of GSH levels compared to the control group. Rats treated with montelukast $10 \mathrm{mg} / \mathrm{kg}$ daily after exposure to WAS for 5 days showed 
regular gastric surface epithelium and gastric glands, mild congestion, some inflammatory cell infiltration and mostly granulated mast cells. The levels of MDA were significantly decreased and GSH were significantly increased in the treated groups. The authors stated that WAS caused damage of gastric mucosa through inflammatory mechanisms evidenced by marked activation and degranulation of mast cells releasing leukotrienes that caused inflammation which was markedly attenuated by montelukast treatment. In addition the authors reported that free oxygen radicals are involved in the pathogenesis of several models of gastric mucosal damage including cold-restrained stress and chronic WAS as shown by a significant increase in gastric MDA levels and significant decrease in GSH levels. They suggested that montelukast's protective effect of gastrointestinal mucosa is due to anti-inflammatory actions and inhibition of release of proinflammatory cytokines as well as antioxidant action [20]. The authors referred to other actions of montelukast as increase prostaglandins production which are cytoprotective to gastric mucosa and decrease of some proinflammatory mediators like endothelin-1 and interferony [21]. Their results agreed with the current work as montelukast treatment with both doses (30 and $60 \mathrm{mg} / \mathrm{kg}$ ) resulted in decrease in mean ulcer score that was significant with the higher dose of montelukast and significant decrease in MDA and increase in SOD. Regenerative changes in the epithelium of gastric mucosa were seen in the group treated with $60 \mathrm{mg} / \mathrm{kg}$.

Also in accordance with our results, Risk et al., demonstrated that administration of dexamethasone to rats for 7 days caused significant increase in gastric tissue malondialdehyde (MDA) levels and superoxide dismutase (SOD) activity. They also demonstrated that dexamethasone treatment caused histopathological changes in the stomach in the form of distorted glands with focal exfoliation of glandular epithelium, edema, areas of hemorrhage, and some mononuclear cells. There was also increase in myeloperoxidase (MPO) activity indicative of infiltration of neutrophils. In addition, they detected decreased mucus production. The authors suggested that gastric damage caused by dexamethasone maybe caused by increased oxidative stress. Administration of montelukast with dexamethasone for 7 days resulted in a significant decrease in MDA levels suggesting that it has an antioxidant effect. They also proposed that montelukast has an anti-inflammatory action as demonstrated by significant decrease in MPO activity of gastric tissue caused by dexamethasone treatment as well as by the improved histopathological picture of the stomach in the form of decreased edema and mononuclear cells. In contrast to the present work where histopathological examination of the stomach showed loss of mucin, the authors reported that montelukast treatment caused increased mucus production in the stomach by unknown mechanisms [22].

The results of the current work showed that dexamethasone caused inhibition of intestinal contractions amplitude in response to acetyl choline. The groups treated with famotidine and montelukast 30 and $60 \mathrm{mg} / \mathrm{kg}$ showed increase in the amplitude of contractility of small intestine to acetyl choline. The highest response was seen in the group treated with high dose of montelukast. Similarly, in a study performed by Şener and colleagues, 2007, ischemia/ reperfusion injury resulted in diminished contractile response of isolated rat urinary bladder strips to carbachol. Treatment with montelukast showed that the contractile responses of the bladder to all concentrations of carbachol were increased. The authors reported that oxidative damage of the bladder as well as inflammation resulted in the diminished response to carbachol. As demonstrated in their work, montelukast decreased MDA level and preserved GSH levels in bladder tissue in addition to decreasing myeloperoxidase enzyme. They stated that the improved contractile response to carbachol in the treated group could be attributed to the antioxidant activity of montelukast and inhibition of neutrophil infiltration [23] .

In accordance, the study performed by Capasso and Loizzo, 2008, showed that dexamethasone dose-dependently caused inhibition of transmurally electrically stimulated guinea pig ileum preparation. The authors noted that it has been previously demonstrated that this inhibitory effect is caused by non-specific spasmolytic effect rather than interference with synthesis of prostaglandins. They also suggested that the inhibitory effects of dexamethasone may be due to its action on membrane bound receptors not linked to DNA responsive elements [24]. In another study, montelukast did not inhibit contractions of isolated guinea pig trachea in response to acetylcholine. Nor did intravenous montelukast antagonize bronchoconstriction induced in anesthetized guinea pigs by acetylcholine [25]. On the other hand, addition of montelukast resulted in relaxation of isolated methacholine induced contracted tracheal strips of rats, but could not inhibit the contraction of isolated trachea caused by electrical field stimulation. The authors stated that electrical field stimulation was believed to be due to stimulation of parasympathetic innervation and they concluded that montelukast in increasing 
concentrations was not able to antagonize parasympathetic innervation responsible for tracheal contraction [26].

On the contrary to the results of the present work, Capasso and Loizzo, 2008 demonstrated that treatment with dexamethasone caused a significant decrease in gastrointestinal propulsion (gastrointestinal transit was $56 \%$ in the dexamethasone treated mice compared to $69 \%$ in the normal saline treated group). However, the authors also demonstrated that treatment with dexamethasone reversed morphine as well as atropine induced constipation. They suggested that this effect could probably be due to dexamethasone enhanced release of acetyl choline [24]. This could explain the results demonstrated in the current work of the increased gastrointestinal transit in the dexamethasone treated rats compared to the normal control group. In addition, it has been shown that water avoidance stress resulted in acceleration of ororcaecal transit and colonic passage in rats $[27,28]$.

Conclusion: Dexamethasone treatment and exposure to cold stress resulted in ulceration and congestion of gastric mucosa, increased intestinal transit and diminished amplitude of intestinal contraction in response to acetyl choline. In addition there was increased oxidative stress in the form of increased MDA and decreased SOD in gastric tissue. Montelukast at both doses was able to reverse the deleterious effects of dexamethasonestress but the results were significant and more pronounced with the higher dose of montelukast which showed a protective effect even more than famotidine. The results of the current work show that montelukast may have a promising role in eliminating the undesirable effect induced by corticosteroids in asthmatic patients in the gastrointestinal tract especially that associated with exposure to stress by its anti-oxidant effect.

\section{Research involving animals:}

All applicable international, national, and/or institutional guidelines for the care and use of animals were followed according to animal ethics of Helsinki.

Conflict of interest: The authors state no conflict of interest in carrying out, reporting or publishing this work.

Authors contribution: Dr. Marian Youssry Wissa and Ghada Farouk performed the practical work, shared in writing; Dr. Heba Morsi performed the biochemical part in the study.
Acknowledgments and funding: I really appreciate the efforts of Dr. Somia Abdulatif Soliman Lecturer of Pathology, Faculty of Medicine, Cairo University, Egypt for performing the pathological part in the study. This work was supported financially by the authors.

\section{References}

1- GUSLANDI M. and TITTOBELLO A.: Steroid ulcers: A myth revisited. British Medical Journal, 304 (6828): 655656, [PMID: 1571634]; [DOI: 10.1136/bmj.304.6828.655a], 1992.

2- de KASKI M.C., RENTSCH R., LEVI S. and HODGSON H.J.: Corticosteroids reduce regenerative repair of epithelium in experimental gastric ulcers. Gut, 37(5): 613-616, [PMID: 8549934]; [DOI: 10.1136/gut.37.5.613], 1995.

3- LUO J.C., SHIN V.Y., LIU E.S., YI N.Y., WU W.K., SO W.H., CHANG F.Y. and CHO C.H.: Dexamethasone delays ulcer healing by inhibition of angiogenesis in rat stomachs. European journal of pharmacology, 485(1-3): 275-281, [PMID: 14757151]; [DOI: 10.1016/j.ejphar. 2003.11.038], 2004.

4- DRAZEN J.M., ISRAEL E. and O'BYRNE P.M.: Treatment of asthma with drugs modifying the leukotriene pathway. New England Journal of Medicine, 340 (3): 197-206, [PMID: 9895400]; [DOI: 10.1 056/NEJM 199901213400306], 1999.

5- SHARMA J.N. and MOHAMMED L.A.: The role of leukotrienes in the pathophysiology of inflammatory disorders: Is there a case for revisiting leukotrienes as therapeutic targets?. Inflammopharmacology, 14 (1-2): 10-16, [PMID: 16835707]; [DOI: 10.1007/s10787-0061496-6], 2006.

6- RAMIRES R., CAIAFFA M.F., TURSI A., HAEGGSTRÖM J.Z. and MACCHIA L.: Novel inhibitory effect on 5-lipoxygenase activity by the anti-asthma drug montelukast. Biochemical and biophysical research communications, 324 (2): 815-821, [PMID: 15474500]; [DOI: 10.1016/j.bbrc.2004.09.125], 2004.

7- TAHAN F., JAZRAWI E., MOODLEY T., ROVATI G. E. and ADCOCK I.M.: Montelukast inhibits tumour necrosis factor- a-mediated interleukin-8 expression through inhibition of nuclear factor- $\mathrm{KB}$ p65-associated histone acetyltransferase activity. Clinical \& Experimental Allergy, 38 (5): 805-811, [PMID: 18325031]; [DOI: 10.1111/j.1365-2222.2008.02963.x], 2008.

8- ANDERSON R., THERON A.J., GRAVETT C.M., STEEL H.C., TINTINGER G.R. and FELDMAN C.: Montelukast inhibits neutrophil pro-inflammatory activity by a cyclic AMP-dependent mechanism. British journal of pharmacology, 156 (1): 105-115, [PMID: 19068077]; [DOI: 10.111 1/j. 1476-538 1.2008.00012.x], 2009.

9- ROBINSON A.J., KASHANIN D., O'DOWD F., WILLIAMS V. and WALSH G.M.: Montelukast inhibition of resting and GM-CSF-stimulated eosinophil adhesion to VCAM-1 under flow conditions appears independent of cysLT1R antagonism. Journal of leukocyte biology, 83 (6): 1522-1529, [PMID: 18332235]; [DOI: 10.1189/ jlb.1007717], 2008. 
10- ALHAZZANI W., ALENEZI F., JAESCHKE R.Z., MOAYYEDI P. and COOK D.J.: Proton pump inhibitors versus histamine 2 receptor antagonists for stress ulcer prophylaxis in critically ill patients: A systematic review and meta-analysis. Critical care medicine, 41(3): 693705, [PMID: 23318494]; [DOI: 10.1097/CCM. 0b013e3182758734], 2013.

11-FILEP J.G., HERMÁN F., FÖLDES-FILEP Ë, SCHNEIDER F. and BRAQUET P.: Dexamethasone-induced gastric mucosal damage in the rat: Possible role of plateletactivating factor. British journal of pharmacology, 105 (4): 912-918, [PMID: 1324056]; [DOI: 10.1111/j.147653 81.1992.tb09077.x], 1992.

12- OZBAK1S -DENGIZ G., CAD1RC1 E. and YURDAKAN G.: Histopathologic evaluation of anti-ulcerogenic effect of montelukast in indomethacin-induced experimental ulcer model. The Turkish journal of gastroenterology, 24(2): 88-92, [PMID: 23934453]; [DOI: 10.4318/tjg. 2013.0711], 2013.

13- PARE W.P. and GLAVIN G.B.: Restraint stress in biomedical research: A review. Neuroscience \& Biobehavioral Reviews, 10 (3): 339-370, [PMID: 3095718], 1986.

14- SANTUCCI L., FIORUCCI S., GIANSANTI M., BRUNORI P.M., DIMATTEO F.M. and MORELLI A.: Pentoxifylline prevents indomethacin induced acute mucosal damage in rats: Role of tumour necrosis factor alpha. Gut, 35 (7): 909-915, [PMID: 8063218]; [DOI: 10.1136/gut. 35.7.909], 1994.

15- UDO N.V., PAUL A.U., HELEN O.T., EFFIOM O.E. and BASSEY A.A.: Crude Aloe vera gel reduces small intestinal transit and increases body weight in normal Albino Wistar rats. Journal of Scientific Research and Reports, 2 (2): 741-753, [DOI: 10.9734/JSRR/2013/5489], 2013.

16- OBEMBE A.O., OKWARI O.O., OWU D.U., ANTAI A.B. and OSIM E.E.: Intestinal motility and transit following chronic ingestion of different forms of palm oil diets. Nigerian Journal of Physiological Sciences, 23 (12): 95-99, [PMID: 19434222], 2008.

17-MALSTROM B., ANDREASSON L. and REINHAMMER B.: The Enzymes, Bayer P., editor XIIB, Academic Press, New York, 533, 1975.

18- MIHARA, M. and UCHIYAMA M.: Determination of malonaldehyde precursor in tissues by thiobarbituric acid test. Analytical Biochemistry, 86 (1): 271-278, [PMID: 655387]; [DOI: 10.1016/0003-2697(78)90342-1], 1978.

19- SWAMY A.H., SAJJAN M., THIPPESWAMY A.H., KOTI B.C. and SADIQ A.J.: Influence of proton pump inhibitors on dexamethasone-induced gastric mucosal damage in rats. Indian Journal of Pharmaceutical Sciences, 73 (2): 193-198, [PMID: 22303063], 2011.

20- ERSOY Y., ÇIKLER E., ÇETINEL S ., S ENER G. and ERCAN F.: Leukotriene D4 receptor antagonist montelukast alleviates water avoidance stress-induced degeneration of the gastrointestinal mucosa. Prostaglandins, Leukotrienes and Essential Fatty Acids, 78 (3): 189-197, [PMID: 18387287]; [DOI: 10.1016/j.plefa.2008.01.007], 2008.

21- FINSNES F., LYBERG T., CHRISTENSEN G. and SKJØNSBERG O.H.: Leukotriene antagonism reduces the generation of endothelin-1 and interferon- $y$ and inhibits eosinophilic airway inflammation. Respiratory medicine, 96 (11): 901-906, [PMID: 12418588]; [DOI: 10.1053/ rmed.2002.1375], 2002.

22- RIZK F.H., IBRAHIM M.A.A., ABD-ELSALAM M.M., SOLIMAN N.A. and ABD-ELSALAM S.M.: Gastroprotective effects of montelukast and Nigella sativa oil against corticosteroid-induced gastric damage: They are much more than antiasthmatic drugs. Canadian journal of physiology and pharmacology, 95 (6): 714-720, [PMID: 28187265]; [DOI: 10.1139/cjpp-2016-0374], 2017.

23- S ENER G., S EHIRLI O., TOKLU H., ERCAN F. and ALICAN I.: Montelukast reduces ischaemia/reperfusioninduced bladder dysfunction and oxidant damage in the rat. Journal of pharmacy and pharmacology, 59 (6): 837842, [PMID: 17637175]; [DOI: 10.1211/jpp.59.6.0009], 2007.

24- CAPASSO A. and LOIZZO A.: Functional interference of dexamethasone on some morphine effects: Hypothesis for the steroid-opioid interaction. Recent patents on CNS drug discovery, 3 (2): 138-150, [PMID: 18537773], 2008.

25- JONES T.R., LABELLE M., BELLEY M., CHAMPION E., CHARETTE L., EVANS J., FORD-HUTCHINSON A.W., GAUTHIER J.Y., LORD A., MASSON P., McAU LIFFE, M., McFARLANE C.S., METTERS K.M., PICKETT C., PIECHUTA H., ROCHETTE C., RODGER I.W., SAWYER N., YOYNG R.N., ZAMBONI R. and ABRAHAM W.M.: Pharmacology of montelukast sodium (SingulairTM), a potent and selective leukotriene D4 receptor antagonist. Canadian journal of physiology and pharmacology, 73 (2): 191-201, [PMID: 7621356]; [DOI: 10.1139/y95-028], 1995.

26- CHENG L.H., KAO C.H., WANG C.H., CHU Y.H., WANG J.Y. and WANG H.W.: Anti-cholinergic effect of singulair on isolated rat's tracheal smooth muscle. European Archives of Oto-Rhino-Laryngology, 269 (8): 1923 1927, [PMID: 22203119]; [DOI: 10.1007/s00405-0111880-8], 2012.

27- ENCK P., MERLIN V., ERCKENBRECHT J.F. and WIEN BECK M.: Stress effects on gastrointestinal transit in the rat. Gut, 30 (4): 455-459, [PMID: 2714679]; [DOI: 10.1136/gut.30.4.455], 1989.

28- SUDA K., SETOYAMA H., NANNO M., MATSUMOTO S. and KAWAI M.: Involvement of parasympathetic pelvic efferent pathway in psychological stress-induced defecation. World journal of Gastroenterology, 19 (8): 1200-1209, [PMID: 23482518]; [DOI: 10.3748/wjg.v 19.i8.1200], 2013. 


\section{كفائة المونتيلوكاست فى تحسين الأثار الضارة

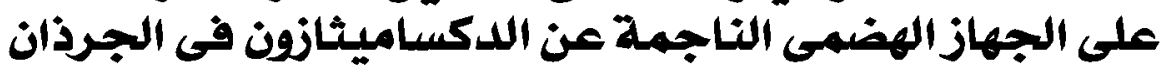

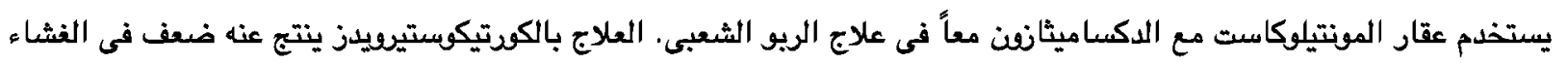

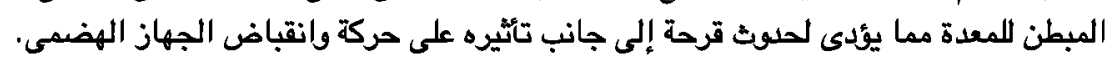

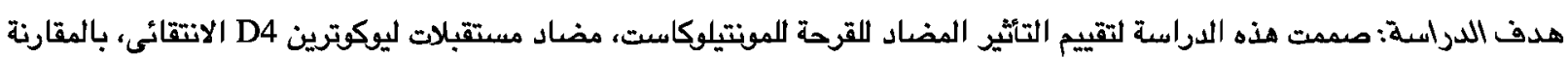

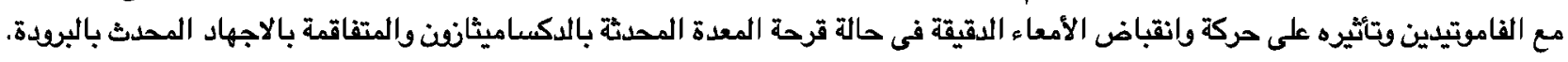

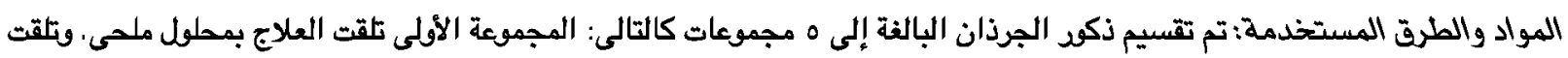

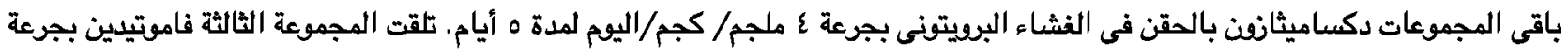

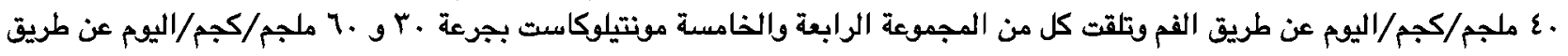

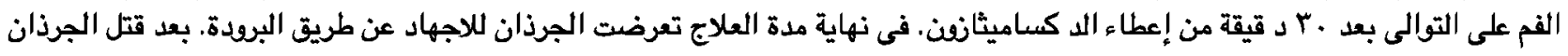

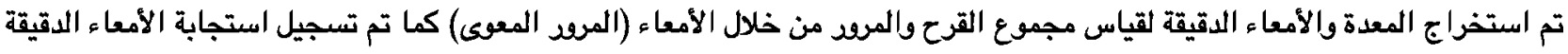

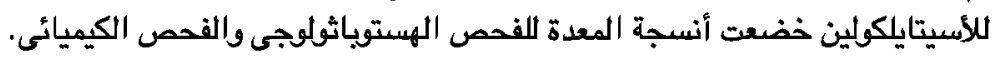

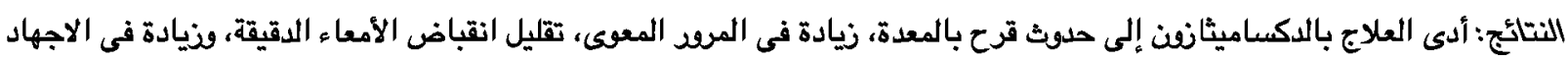

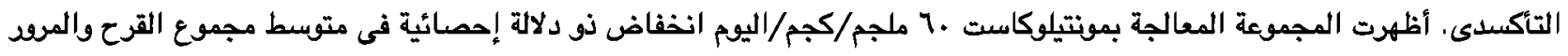

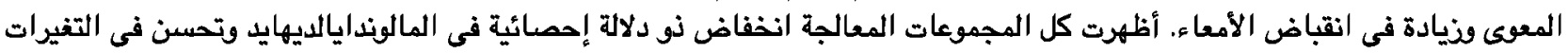

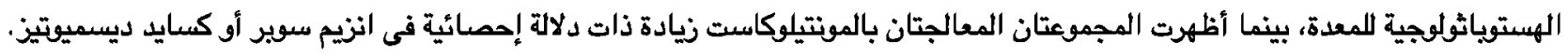

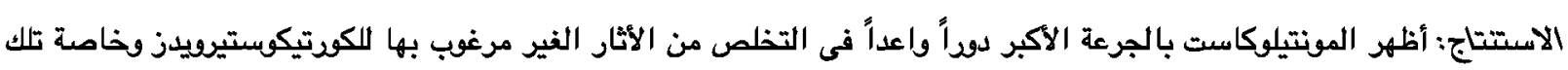
المصاحبة للتعرض للاجهاد. 